\title{
Pathological study of chronic pulmonary toxicity induced by intratracheally instilled Asian sand dust (Kosa): possible association of fibrosis with the development of granulomatous lesions
}

\author{
Akinori Shimada', Yukari Kohara ${ }^{2}$, Misaki Naota ${ }^{2}$, Yoshimi Kobayashi², \\ Takehito Morita ${ }^{2}$, Kenichiro Inoue ${ }^{3}$, Hirohisa Takano ${ }^{4}$ \\ ${ }^{1}$ Laboratory of Pathology, School of Life and Environmental Science, Azabu University, Kanagawa, Japan \\ ${ }^{2}$ Department of Veterinary Pathology, Tottori University, Tottori, Japan \\ ${ }^{3}$ School of Nursing, University of Shizuoka, Shizuoka, Japan \\ ${ }^{4}$ Department of Environmental Engineering, Kyoto University Graduate School of Engineering, \\ Kyoto, Japan
}

\begin{abstract}
Introduction. Exposure to Asian sand dust (ASD) is associated with enhanced pulmonary morbidity and mortality, and the reporting of such cases has rapidly increased in East Asia since 2000. The purpose of the study was to assess chronic lung toxicity induced by ASD.

Material and methods. A total of 174 ICR mice were randomly divided into 5 control and 17 exposure groups. Suspensions of low dose $(0.2,0.4 \mathrm{mg})$ and high dose $(3.0 \mathrm{mg})$ of ASD particles in saline were intratracheally instilled into ICR mice, followed by sacrifice at 24 hours, 1 week, and 1, 2, 3 and 4 months after instillation. Paraffin sections of lung tissues were stained with hematoxylin and eosin and by immunohistochemistry to detect $\alpha$-smooth muscle actin, collagen III, matrix metalloproteinase-9 (MMP-9), tissue inhibitor of metalloproteinases-1 (TIMP-1), CD3, CD20, immunoglobulin G, interleukin- $\beta$ and inducible nitric oxide synthase.

Results. A lung histological examination revealed similar patterns in the lesions of the groups treated with high $(3.0 \mathrm{mg})$ or low dose $(0.4 \mathrm{mg})$ of ASD. Acute inflammation was observed $24 \mathrm{~h}$ after treatment and subsided after 1 week; persistent granulomatous changes were observed at 2 months, focal lymphocytic infiltration at 3 months, and granuloma formation at 4 months. An increase in the size of granulomatous lesions was observed over time and was accompanied by collagen deposition in the lesions. The cytoplasm of macrophages in inflammatory lesions showed positive immunolabeling for MMP-9 at $24 \mathrm{~h}, 1$ and 2 months after instillation of $3.0 \mathrm{mg}$ of ASD. Positive immunolabeling for TIMP-1 was demonstrated in the cytoplasm of macrophages at 2 and 4 months after instillation of $3.0 \mathrm{mg}$ of ASD. These findings suggest association between the expression of MMP-9 and TIMP-1 with the development of lung granulomatous lesions.

Conclusions. These findings suggest that collagen deposition resulting from the altered regulation of extracellular matrix is associated with granuloma formation in the lungs of mice treated with ASD. (Folia Histochemica et Cytobiologica 2015, Vol. 53, No. 4, 294-306)
\end{abstract}

Key words: Asian sand dust; chronic toxicity; lung; granuloma; MMP-9; TIMP-1; macrophages; CD3; CD20

Correspondence address: Prof. A. Shimada, D.V.M., Ph.D.

Laboratory of Pathology, School of Life and Environmental Science, Azabu University, 1-17-71 Fuchinobe,

Sagamihara-shi, Kanagawa 252-5201, Japan,

tel.: +8142754 7111,

e-mail: a-shimada@azabu-u.ac.jp

\section{Introduction}

Asian sand dust (ASD; known as Kosa aerosol) originating from the arid deserts of Mongolia and China causes severe air pollution annually in the Asia-Pacific area, including China, Korea, and Japan 1 [1]. Epide- 
miological studies of ASD in humans have shown that exposure to ambient ASD particles is associated with an increase in pulmonary [2-6] and cardiovascular problems [2, 3, 7, 8], and increased mortality in Korea [9-12] and Taiwan [13]. The frequency and scale of dust events giving rise to ASD aerosols have increased rapidly in East Asia since 2000 [14]. Because of recent environmental changes such as desertification and global warming, human and animals are at increased risk of frequent exposure to ASD and the resultant adverse health effects of ASD on the respiratory system.

A previous study [15] reported that the major mineralogical component of ASD is silica $\left(\mathrm{SiO}_{2}\right)$. Occupational exposure to crystalline silica is associated with silicosis, lung cancer, pulmonary tuberculosis, and chronic obstructive pulmonary disease [16]. In addition, patients with silicosis often develop autoimmune diseases $[17,18]$. It has been reported that experimental chronic exposure to crystalline silica caused granuloma formation [19-23] and/or fibrosis [24] in rats. In addition, granulomatous inflammation, which is characterized by the accumulation of epithelioid macrophages containing crystalline silica particles in the tracheobronchial lymph nodes, has been reported in rats exposed to crystalline silica $[20,25,26]$.

Previous studies on pulmonary toxicity caused by intratracheally instilled high doses of ASD demonstrated that the mineralogical components of ASD particles, free from chemical and biological pollutants, caused acute inflammatory changes in lung tissues [27-29]. Indeed, these chronic changes were similar to those observed in the silica exposure study: focal infiltration of lymphocytes with an accumulation of epithelioid macrophages and granuloma formation in the lung, and aggregation of macrophages containing particles in the tracheobronchial lymph nodes, 2 and 3 months after instillation. These findings suggested that precautions should be taken to minimize exposure to ASD. Additionally, more experimental studies using the inhalation method with lower doses of ASD to mimic the natural low-level exposure occurring during the Kosa event season should be conducted in the future.

The purpose of the current study was to describe the chronic lung toxicity induced by intratracheally instilled low doses of ASD in mice and to elucidate the pathomorphogenesis of granuloma formation.

\section{Material and methods}

Animals. A total of 174 male ICR mice (5 or 6 weeks old) were obtained from CLEA JAPAN Inc. (Tokyo, Japan). Animals were fed a CE-2 diet purchased from CLEA JAPAN, and water was provided ad libitum. The mouse cages were housed at a temperature of about $25^{\circ} \mathrm{C}$ with $55-70 \%$ humidity. All animal experiments were performed according to the Tottori University guidelines for animal welfare (http://www.tottori-u.ac.jp/kouhou/kisokusyuu/reiki_honbun/u0950581001.html). Body weight changes were recorded weekly to assess general health.

Preparation of particle samples. CJ-2 particles, which are simulated ASD particles were used in this study. The CJ-2 particles were obtained from General Science Corporation (Tokyo, Japan). The particles were collected from the surface soil in the southwest part of the Tengger desert in north-central China where dust storms occur frequently [15]. The CJ-2 particles contain $28.0 \% \mathrm{Si}, 5.9 \% \mathrm{Al}, 5.3 \% \mathrm{Ca}$, $3.0 \% \mathrm{Fe}, 1.7 \% \mathrm{~K}$, and $1.6 \% \mathrm{Mg}$, and the mean diameter of the particles was approximately $0.03 \mathrm{~mm} \pm 0.01 \mathrm{~mm}$, according to the manufacturer's data sheet. The CJ-2 particles were hot-air sterilized at $300^{\circ} \mathrm{C}$ for 1 hour to remove toxic substances (microbiological substances as well as chemicals including nitrogen oxide and sulfur oxide) adhering to ASD. The sterilization temperature was determined in accordance with previous studies [27]. It has been reported that neither the chemical composition nor the shape of mineral particles changed even when heated to $700^{\circ} \mathrm{C}[30]$.

Preparation of ASD suspensions. The sterilized particles were suspended in $0.05 \mathrm{~mL}$ of sterilized saline solution for instillation. The suspensions were deflocculated via ultrasonic disintegration for 3 minutes. Three doses (low doses: 0.2 and $0.4 \mathrm{mg}$; high dose: $3.0 \mathrm{mg}$ ) of the particles were chosen to determine dose effects on lung toxicity in mice. The maximum deposition of particles in the lung of a single mouse was calculated using tidal volume and breathing rate [27]. The maximum weekly deposition of suspended particulate matter $\left(0.1 \mathrm{mg} / \mathrm{m}^{3}\right)$, as measured by the Japanese national air quality standard, was approximately $0.03 \mathrm{mg}$. The instillation doses $(0.2,0.4$ and $3.0 \mathrm{mg})$ in the present study represent 6.6, 13.2 and 99 times that amount, respectively [28]. Control mice received $0.05 \mathrm{~mL}$ of a saline solution.

Study protocol. A total of 174 mice were randomly divided into 5 control and 17 exposure groups (Table 1). The mice were anesthetized by an intraperitoneal injection of sodium pentobarbital (5 mg/100 g body weight). The suspensions were agitated immediately before intratracheal instillation, and $0.05 \mathrm{~mL}$ of the suspension was instilled with an intratracheal cannula in each mouse. Each intratracheal instillation procedure took 3 seconds.

The animals in each group were euthanized by exsanguination under deep anesthesia induced by intraperitoneal injection of sodium pentobarbital at 24 hours, 1 week, and 1, 2, 3 and 4 months after instillation.

Pathological examination. Four mice from each control group and five to ten mice from each particle-treated group were used for pathological examination (Table 1). On dissection, the trachea was immediately exposed and $0.5 \mathrm{~mL}$ 
Table 1. Number of animals exposed to Asian sand dust particles and examined after time indicated

\begin{tabular}{|l|c|c|c|c|c|c|}
\hline Groups & \multicolumn{6}{|c|}{ Post-exposure time } \\
\hline & $\mathbf{2 4}$ hours & 1 week & 1 month & 2 months & 3 months & 4 months \\
\hline Control (saline) & 4 & 4 & 4 & 4 & 4 & NE \\
\hline ASD 0.2 mg & 10 & 10 & 10 & 10 & 8 & NE \\
\hline ASD 0.4 mg & 9 & 10 & 10 & 10 & 8 & 11 \\
\hline ASD 3.0 mg & 5 & 7 & 7 & 10 & 9 & 10 \\
\hline Total & 28 & 31 & 31 & 34 & 29 & 21 \\
\hline
\end{tabular}

Animals were treated as described in Material and methods. ASD — Asian sand dust; NE — not examined

of $10 \%$ neutral-buffered formalin was instilled gently with the use of syringe via the tracheal cannula at low pressure; formalin injection was carried out within 15 min after death. Whole lungs were removed and fixed by immersion in $10 \%$ neutral-buffered formalin for 1 day. Then, the lung lobes were separated, and transverse sections from each lobe were made. These transverse sections and tracheobronchial lymph nodes were placed into embedding cassettes and fixed by immersion in $10 \%$ neutral-buffered formalin for 3 days. Formalin-fixed tissues of lungs and tracheobronchial lymph nodes were routinely processed and embedded in paraffin for histopathological and immunohistochemical examination. Sections approximately $3-\mu \mathrm{m}$ thick were cut and stained with hematoxylin and eosin ( $\mathrm{H} \& \mathrm{E})$. Pathological evaluations were performed by 2 pathologists. The area of each granuloma was measured by using the polygon area measurement function of a microscope digital camera DP21 (Olympus, Tokyo, Japan). The number of granulomas in the lung of each mouse was determined.

Immunohistochemistry: polymer method. Paraffin-embedded sections of the lungs of mice treated with saline alone or with $3.0 \mathrm{mg}$ of ASD particles were used for immunohistochemical detection of $\alpha$-smooth muscle actin ( $\alpha$-SMA), collagen III, matrix metalloproteinase-9 (MMP-9), tissue inhibitor of metalloproteinases-1 (TIMP-1), CD3 (T lymphocyte marker), CD20 (B lymphocyte marker), immunoglobulin $\mathrm{G}$, interleukin- $1 \beta$ (IL- $1 \beta$ ) and inducible nitric oxide synthase (iNOS). For antigen retrieval, the sections were placed in citrate buffer solution ( $\mathrm{pH}$ 5.4) and microwaved for 20 minutes. Endogenous peroxidase activity was quenched with $3 \% \mathrm{H}_{2} \mathrm{O}_{2}$ for 30 minutes at room temperature. The slides were then blocked with $10 \%$ normal goat serum for one hour at room temperature. Thereafter, the sections were incubated in primary antibodies overnight at $4^{\circ} \mathrm{C}$ (anti- $\alpha$ SMA, Dako, Glostrup, Denmark, 1:80 dilution; anti-collagen III, Cosmo Bio Co. Ltd, Tokyo, Japan, 1:20,000 dilution; anti-MMP-9, Bioss, Boston, USA, 1:200 dilution; anti-TIMP-1, Bioss, 1:100 dilution; anti-CD3, Dako, Glostrup, Denmark, 1:400 dilution; anti-CD20, Thermo Fisher Scientific, CA, USA, 1:500 dilution; anti-mouse immunoglobulins, Dako,
1:300 dilution; anti-IL-1 $\beta$, Santa Cruz Biotechnology, CA, USA, 1:50 dilution; and anti-iNOS, Abcam, Cambridge, UK, 1:100 dilution). The primary antibodies were replaced with phosphate-buffered saline (PBS) in negative controls. After incubation with primary antibodies, the sections were placed in a solution containing a peroxidase-labeled polymer conjugated to secondary anti-mouse and -rabbit antibodies (EnVision + kit/HRP, Dako) for $30 \mathrm{~min}$ at RT temperature. The positive reactions resulted in brown staining with 3,3'-diaminobenzidine tetrahydrochloride (DAB, Wako, Osaka, Japan) as a chromogen, and the sections were counterstained with hematoxylin.

Statistical analysis. All data were expressed as the mean \pm standard deviation. Statistical analysis of the histopathological changes was performed using a Student's t-test for two-group comparisons. For all comparisons, $p$ values less than $5 \%(p<0.05)$ were considered statistically significant.

\section{Results}

\section{Gross findings of the lungs}

At 3 and 4 months after instillation of $3.0 \mathrm{mg}$ of ASD particles, the surface of the lungs was rough. In addition, multiple tiny whitish foci were observed in the parenchyma and surface of the lung. No significant changes were observed in the other treated groups.

\section{Histopathology of the lungs}

Histological sections from control animals instilled with saline showed normal bronchiolar and alveolar architectures at all times examined. In histological sections from animals instilled with ASD particles, the particles were observed in the lungs at all times examined in all treated groups. The number of coarse particles detected at low magnification $(\times 4)$ in the lung was consistent throughout the different time points in each treated group. Fine particles were also observed throughout the lungs in each treated group. Furthermore, the multifocal 
Table 2. Results of the quantitative analysis of the histopathological changes in the lungs of mice at 2,3 and 4 months after Asian sand dust (ASD) instillation

\begin{tabular}{|c|c|c|c|c|c|c|}
\hline Groups & ASD dose & $\begin{array}{c}\text { Lymphocytic } \\
\text { infiltration }(\%)^{1}\end{array}$ & $\begin{array}{l}\text { Infiltration of } \\
\text { mott cells }(\%)^{2}\end{array}$ & $\begin{array}{c}\text { Granuloma } \\
\text { formation }(\%)^{3}\end{array}$ & $\begin{array}{l}\text { The number of } \\
\text { granulomatous lesions }{ }^{4}\end{array}$ & $\begin{array}{l}\text { The area of each } \\
\text { granuloma }\left(\mu \mathbf{m}^{2}\right)^{5}\end{array}$ \\
\hline \multirow{2}{*}{2 months } & $0.4 \mathrm{mg}$ & 0 & 0 & 10 & $0.1 \pm 0.32$ & $3.68 \pm 2.31$ \\
\hline & $3.0 \mathrm{mg}$ & 60 & 10 & 60 & $3.87 \pm 3.74$ & $1.36 \pm 0.35$ \\
\hline \multirow{2}{*}{3 months } & $0.4 \mathrm{mg}$ & 12.5 & 0 & 0 & 0 & - \\
\hline & $3.0 \mathrm{mg}$ & 10 & 78 & 89 & $15.9 \pm 11.9$ & $2.23 \pm 1.57$ \\
\hline \multirow{2}{*}{4 months } & $0.4 \mathrm{mg}$ & 18 & 18 & 45 & $7.09 \pm 5.74$ & $1.61 \pm 0.77$ \\
\hline & $3.0 \mathrm{mg}$ & 40 & 60 & 100 & $14 \pm 8.10$ & $4.11 \pm 2.86$ \\
\hline
\end{tabular}

Percentage of animal which showed ${ }^{1}$ lymphocytic infiltration, ${ }^{2}$ infiltration of plasma cells containing Russell bodies (mott cells), and ${ }^{3}$ granuloma formation; ${ }^{4}$ the number of granulomatous lesions per lung; ${ }^{5}$ average area of each granuloma; ${ }^{4,5}$ values are the mean \pm standard deviation

accumulation of particles, predominantly around the bronchioles, was observed at all times examined after treatment (Supplementary Figure 1). Inflammatory changes were observed around the particles; the intensity and frequency of the inflammation tended to increase with the amount of particles instilled (Supplementary Figure 1). There were no signs of infection in the lungs of any mice used in this study.

At 24 hours after instillation, the thickening of the alveolar wall accompanied by acute inflammatory changes, such as the infiltration of neutrophils and macrophages into the alveoli and bronchoalveolar junction, was observed in all treated groups (Supplementary Figure 1A, B).

At 1 week after instillation, the size of inflammatory foci was similar to that observed in lungs taken at 24 hours after instillation (Supplementary Figure 1C,D). The inflammatory foci were primarily composed of spindle-shaped to elongated cells, macrophages and a small number of neutrophils in all treated groups. Inflammatory foci containing a small number of macrophages were also observed in all treated groups.

At 1 month after instillation, the size of inflammatory foci observed in the lungs seemed to be smaller than those at 1 week after instillation (Supplementary Figure 1E, F). Inflammatory foci were composed of macrophages and occasional multinucleated giant cells.

In addition to the inflammatory responses observed in the lungs at 1 month after instillation, lung changes were reported in $60 \%$ of mice treated with $3.0 \mathrm{mg}$ of ASD, at 2 months after instillation. These included the infiltration of lymphocytes and foamy macrophages around the blood vessels and bronchioli. Small granulomas, which were nodular foci of tightly clustered epithelioid macrophages and occasional multinucleated giant cells, were observed in the lungs of $10 \%$ of mice treated with $0.4 \mathrm{mg}$ and $60 \%$ of those treated with $3.0 \mathrm{mg}$ of ASD, at 2 months after instillation (Supplementary Figure 1H, Table 2). Focal aggregations of macrophages containing fine particles without large particles were noted in the lungs of all treated groups of mice sacrificed at 2 to 4 months after instillation.

At 3 months after instillation of ASD, granulomatous lesions of various sizes and the infiltration of lymphocytes were observed in the $3.0 \mathrm{mg}$ treated group. The number and size of granulomatous lesions increased over time from 2 to 3 months after instillation (Table 2); granuloma formation was observed in $89 \%$ of mice treated with $3.0 \mathrm{mg}$ of ASD. The granulomas were composed of epithelioid cells, macrophages, multinucleated giant cells, neutrophils and large ASD particles (Supplementary Figure 1J). Lymphocytic infiltration was observed in $12.5 \%$ of mice treated with $0.4 \mathrm{mg}$ of particles at 3 months after instillation (Supplementary Figure 1I, Supplementary Figure 2A, C, D, Table 2). Focal accumulation of large foamy macrophages (Supplementary Figure 2B), necrotic cells with scattered fine particles (Supplementary Figure 2A), neutrophils and epithelioid macrophages were occasionally observed; these findings were similar to those reported at 2 months after instillation in the group treated with $3.0 \mathrm{mg}$ of ASD (Supplementary Figure $1 \mathrm{H})$. In addition, scattered plasma cells containing Russell bodies (mott cells) [31] were observed around bronchioles at 3 months after instillation in the group treated with $3.0 \mathrm{mg}$ of ASD.

At 4 months after instillation in the $3.0 \mathrm{mg}$ treated group, the size of the granulomatous lesions were larger than those observed at 3 months, although the number of granuloma per mouse was almost the same (Table 2). Spindle-shaped cells appeared in the granulomatous lesions again and the volume of the interstitium of granulomatous lesions increased (Supplementary Figure 3A). Granuloma formation was observed in $45 \%$ of mice treated with $0.4 \mathrm{mg}$ 
(Supplementary Figure 1K, Table 2) and $100 \%$ of mice treated with $3.0 \mathrm{mg}$ of the particles (Supplementary Figure 1L, Table 2). In addition, lymphoid hyperplasia of bronchus-associated lymphoid tissue (BALT) with aggregation of macrophages containing fine particles and mott cells was observed at 4 months after instillation in both high and low dose treated groups (Supplementary Figure 4A-C).

\section{Histopathology of the tracheobronchial lymph nodes}

Histological sections of the tracheobronchial lymph nodes from control animals instilled with normal saline showed no significant changes at all time examined after treatment.

At 24 hours and 1 week after instillation, mild infiltration of neutrophils in the tracheobronchial lymph nodes was observed in all treated groups. At 1 month after instillation, macrophages containing fine particles were present in the marginal sinus of the tracheobronchial lymph nodes in the $3.0 \mathrm{mg}$ treated group. At 2 months after instillation, macrophages containing fine particles were frequently observed in the entire area of the tracheobronchial lymph nodes in the $3.0 \mathrm{mg}$ treated group. At 3 and 4 months after instillation, focal aggregations of macrophages containing fine particles were seen in the tracheobronchial lymph nodes in the $3.0 \mathrm{mg}$ treated group. In the $0.4 \mathrm{mg}$ treated group, macrophages that contained particles were present in the tracheobronchial lymph nodes at 4 months after instillation.

\section{Immunohistochemical examination of the lungs}

The results of the immunohistochemical examination of the lungs of mice exposed to ASD are presented in Table 3 and Figures 1-4.

\section{$\alpha-S M A$}

Spindle-shaped to elongated cells in the inflammatory foci at 1 week and 4 months after $3.0 \mathrm{mg}$ of ASD instillation showed positive immunolabeling for $\alpha$-SMA (Supplementary Figure 3C). Positive immunolabeling was not observed in inflammatory foci at the other time points examined.

\section{Collagen III}

Fibrillar component in the interstitium of the granulomatous lesions at 4 months after treatment with $3.0 \mathrm{mg}$ ASD showed positive immunolabeling for collagen III (Supplementary Figure 3D).

\section{MMP-9}

The cytoplasm of macrophages in inflammatory lesions showed positive immunolabeling for MMP-9 at 24 hours (Figure 1A), 1 (Figure 1C) and 2 months (Figure 1D) after instillation of $3.0 \mathrm{mg}$ of ASD. However, at 1 week (Figure 1B), 3 (Figure 1E) and 4 months (Figure 1F) after instillation of $3.0 \mathrm{mg}$ of ASD, no positive staining for MMP-9 was observed in the granulomatous lesions.

\section{TIMP-1}

The cytoplasm of macrophages showed positive immunolabeling for TIMP-1 at 2 (Figure 2D) and 4 months (Figure 2F) after $3.0 \mathrm{mg}$ of ASD instillation. Positive immunolabeling was not observed in the inflammatory foci of the other time points examined (Figure 2A-C, E).

\section{CD3 and CD20}

At 2 months after treatment with $3.0 \mathrm{mg}$ of ASD and at 3 months after treatment with $0.4 \mathrm{mg}$ of ASD,

Table 3. Summary of the immunohistochemical findings in lungs of mice treated with $3.0 \mathrm{mg}$ of Asian sand dust particles

\begin{tabular}{|l|l|c|c|c|c|c|c|}
\hline \multirow{2}{*}{} & \multirow{2}{*}{ Localization } & \multicolumn{6}{c|}{ Time after ASD instillation } \\
\cline { 3 - 8 } & & $\mathbf{2 4}$ hours & $\mathbf{1}$ week & $\mathbf{1}$ month & $\mathbf{2}$ months & $\mathbf{3}$ months & $\mathbf{4}$ months \\
\hline MMP-9 & Macrophages & + & - & + & ++ & \pm & \pm \\
\hline TIMP-1 & Macrophages & - & - & - & + & - & ++ \\
\hline Collagen III & Interstitium & NE & NE & NE & NE & NE & + \\
\hline$\alpha$-SMA & Spindle-shaped cells & - & + & - & - & - & + \\
\hline Immunoglobulin G & Lymphocytes & NE & NE & NE & NE & NE & ++ \\
\hline CD3 & T-lymphocytes & NE & NE & NE & +++ & NE & +++ \\
\hline CD20 & B-lymphocytes & NE & NE & NE & + & NE & ++ \\
\hline IL-1 $\beta$ & Macrophages & + & - & + & + & + & + \\
\hline iNOS & Macrophages & + & + & - & +++ & + & + \\
\hline
\end{tabular}

Abbreviations: $\alpha$-SMA — alpha-smooth muscle actin; ASD — Asian sand dust; IL- $1 \beta$ — interleukin- $1 \beta$; MMP-9 — matrix metalloproteinase-9; TIMP-1 — tissue inhibitor of metalloproteinases-1; iNOS — inducible nitric oxide synthase; NE — not examined 


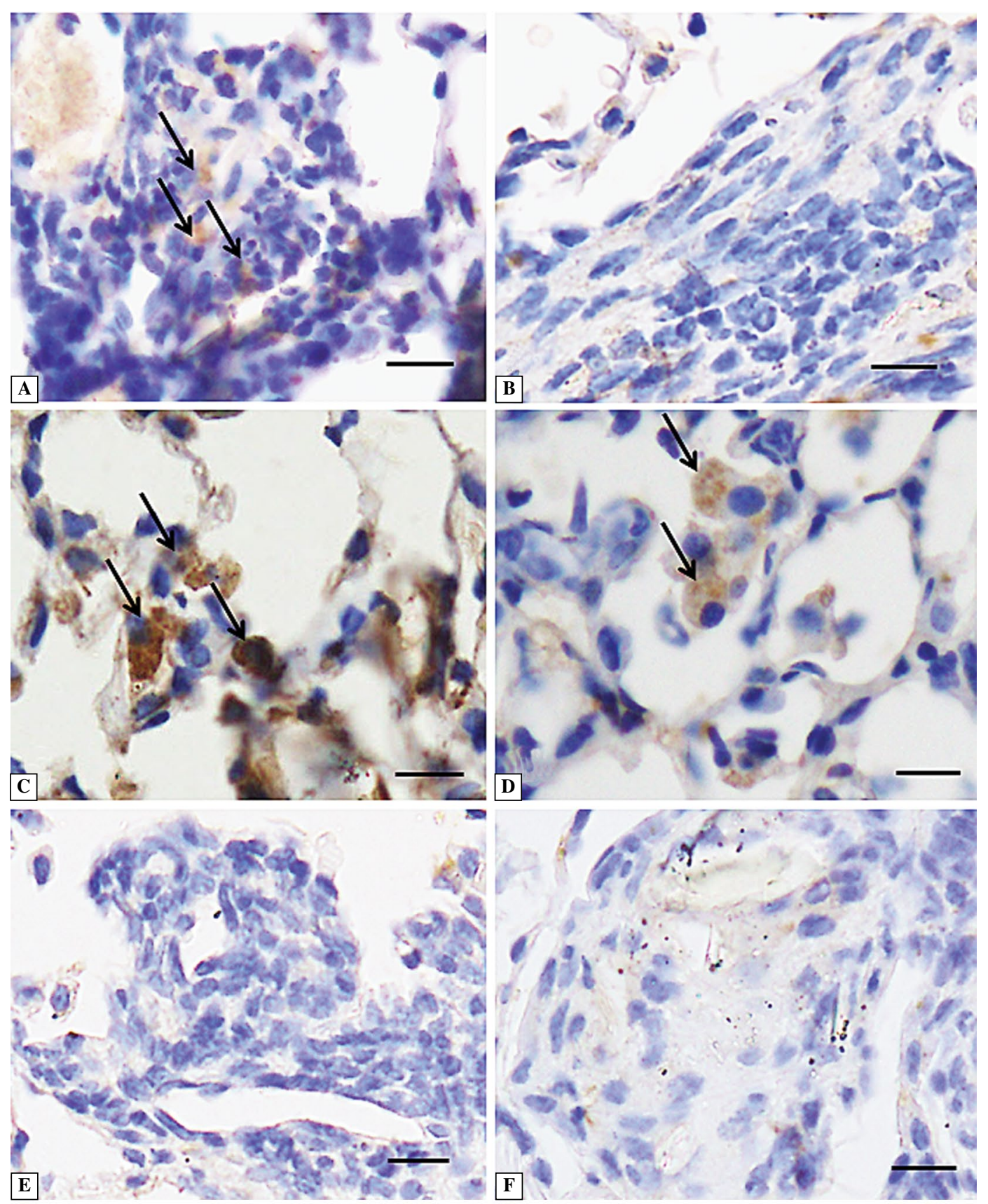

Figure 1. Matrix metalloproteinase (MMP)-9 immunohistochemistry in the lungs of mice treated with $3.0 \mathrm{mg}$ of Asian sand dust at 24 hours (A), 1 week (B), 1 month (C), 2 months (D), 3 months (E) and 4 months (F) after instillation.

A. Macrophages (arrows) in the inflammatory lesions show positive immunolabelings for MMP-9; B, E, F. Inflammatory lesions show negative immunolabeling for MMP-9; C, D. Scattered alveolar macrophages (arrows) show positive immunolabelings for MMP-9. Bars $=20 \mu \mathrm{m}$

many lymphocytes observed around blood vessels and bronchioles showed positive immunolabeling for CD3 (Supplementary Figure 2C). Some scattered lymphocytes in the same lesions showed positive immunolabeling for CD20 (Supplementary Figure 2D).

\section{Immunoglobulin $G$}

The cytoplasm of lymphocytes, accumulated around bronchioles at 4 months after treatment with $3.0 \mathrm{mg}$ of ASD, showed positive immunolabeling for immunoglobulin G (Supplementary Figure 4D).

\section{Interleukin-1 $\beta$ (IL-1 $\beta)$}

The cytoplasm of macrophages in the inflammatory lesions at 24 hours after instillation of $3.0 \mathrm{mg}$ of ASD showed positive immunolabeling for IL-1 $\beta$ (Figure 3A). Inflammatory lesions were negative for IL- $1 \beta$ at 


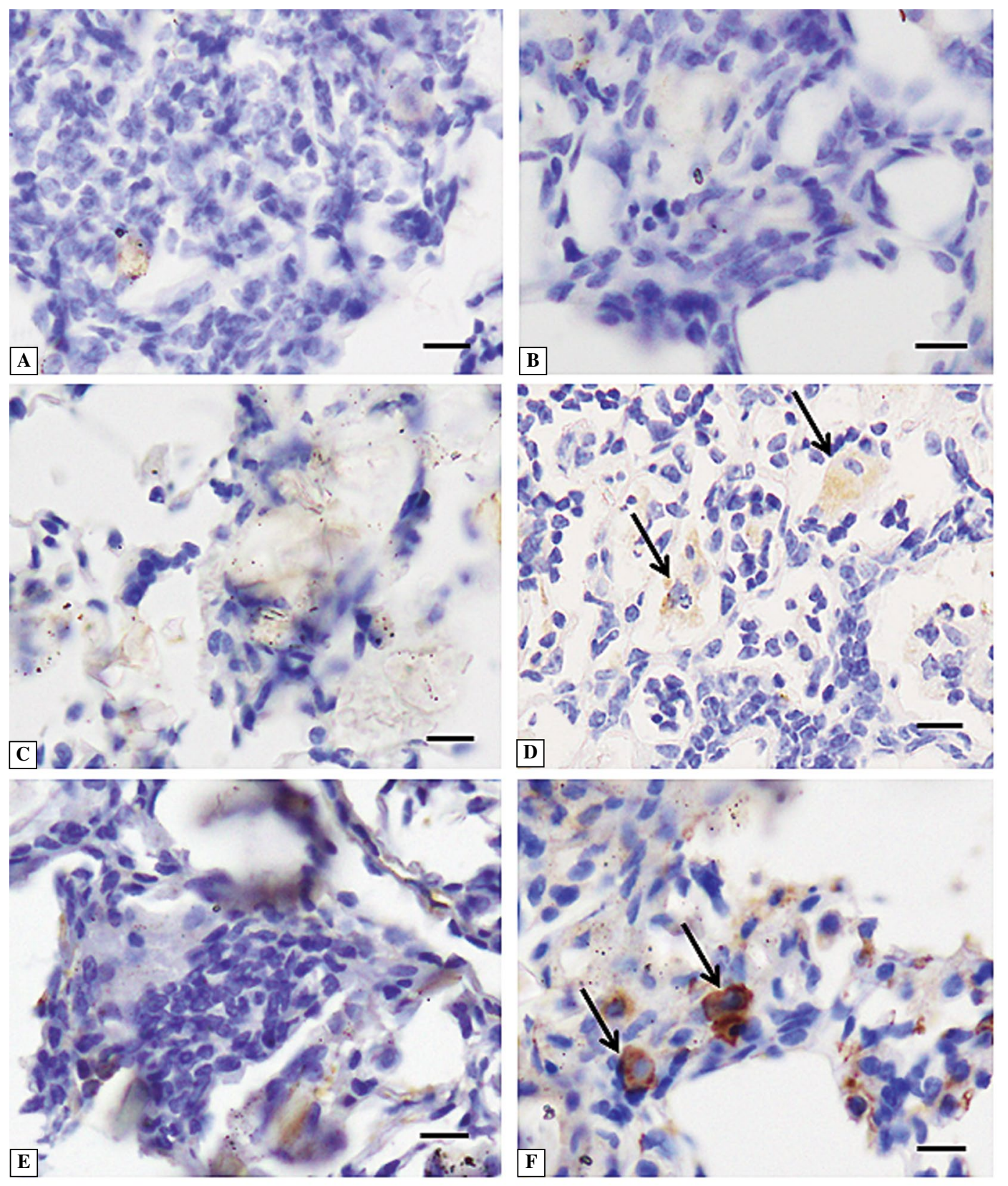

Figure 2. Immunoreactivity of tissue inhibitor of metalloproteinases (TIMP)-1 in lungs of mice treated with $3.0 \mathrm{mg}$ of Asian sand dust at 24 hours (A), 1 week (B), 1 month (C), 2 months (D), 3 months (E) and 4 months (F) after instillation. A-C, E. Inflammatory lesions show negative immunolabelings for TIMP-1; D. Large foamy macrophages (arrows) show moderately positive immunolabeling for TIMP-1; F. Alveolar macrophages (arrows) in the granulomatous lesions show strong positive immunolabelings for TIMP-1. Bars $=20 \mu \mathrm{m}$

1 week after treatment with $3.0 \mathrm{mg}$ of ASD (Figure 3B). At 1 (Figure 3C), 2 (Figure 3D), 3 (Figure 3E) and 4 months (Figure 3F) after treatment with $3.0 \mathrm{mg}$ of ASD, macrophages showed positive immunolabeling for IL-1 $\beta$.

\section{iNOS}

The cytoplasm of macrophages in inflammatory foci at 24 hours (Figure 4A) and 1 week (Figure 4B) after instillation of $3.0 \mathrm{mg}$ of ASD showed positive immunolabeling for iNOS. Inflammatory lesions at 1 month (Figure 4C) after treatment with $3.0 \mathrm{mg}$ of ASD were negative for iNOS. At 2 months after instillation of $3.0 \mathrm{mg}$ of ASD, many macrophages in the inflammatory lesion showed strong positive immunolabeling for iNOS (Figure 4D). At 3 and 4 months after instillation, macrophages in granulomatous lesions (Figure 4E, F) showed positive immunolabeling for iNOS. 


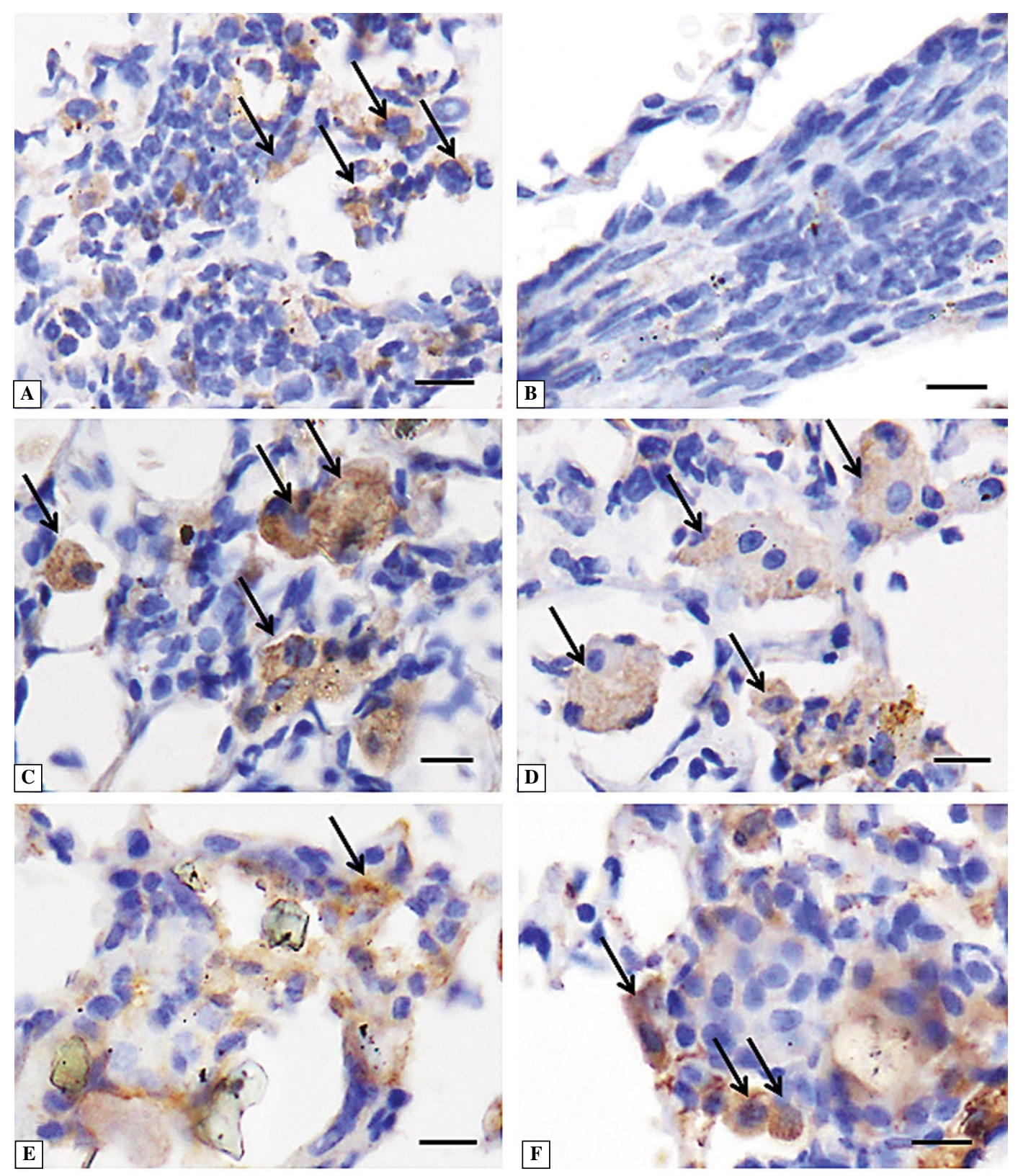

Figure 3. Interleukin (IL)- $1 \beta$ immunoreactivity in lungs of mice treated with $3.0 \mathrm{mg}$ of Asian sand dust at 24 hours (A), 1 week (B), 1 month (C), 2 months (D), 3 months (E) and 4 months (F) after instillation. A, C, D. Alveolar macrophages (arrows) in the inflammatory lesions show positive immunolabelings for IL-1 $\beta$; B. Inflammatory lesions show negative immunolabelings for IL- $1 \beta$; E, F. Macrophages (arrows) in the granulomatous lesions show positive immunolabelings for IL- $1 \beta$. Bars $=20 \mu \mathrm{m}$

\section{Discussion}

Chronic pulmonary toxicity induced by intratracheal instillation of the mineral component of low doses $(0.2,0.4 \mathrm{mg})$ of ASD particles or a high dose $(3.0 \mathrm{mg})$ of ASD particles, free from chemical and biological substances, was pathologically examined in this study. Both acute (examined at 24 hours and 1 week) or chronic (3 months and 4 months) pulmonary inflam- matory changes in lungs exposed to low doses of ASD were evaluated. ASD caused acute inflammatory changes in the lung 24 hours after instillation. The changes were transient and subsided at 1 week following treatment. After this period, the lung lesions seemed to diminish; only minor foci were occasionally observed at 1 and 2 months after instillation. Exacerbation of inflammation, which is characterized by the infiltration of lymphocytes, was, however, occasionally 

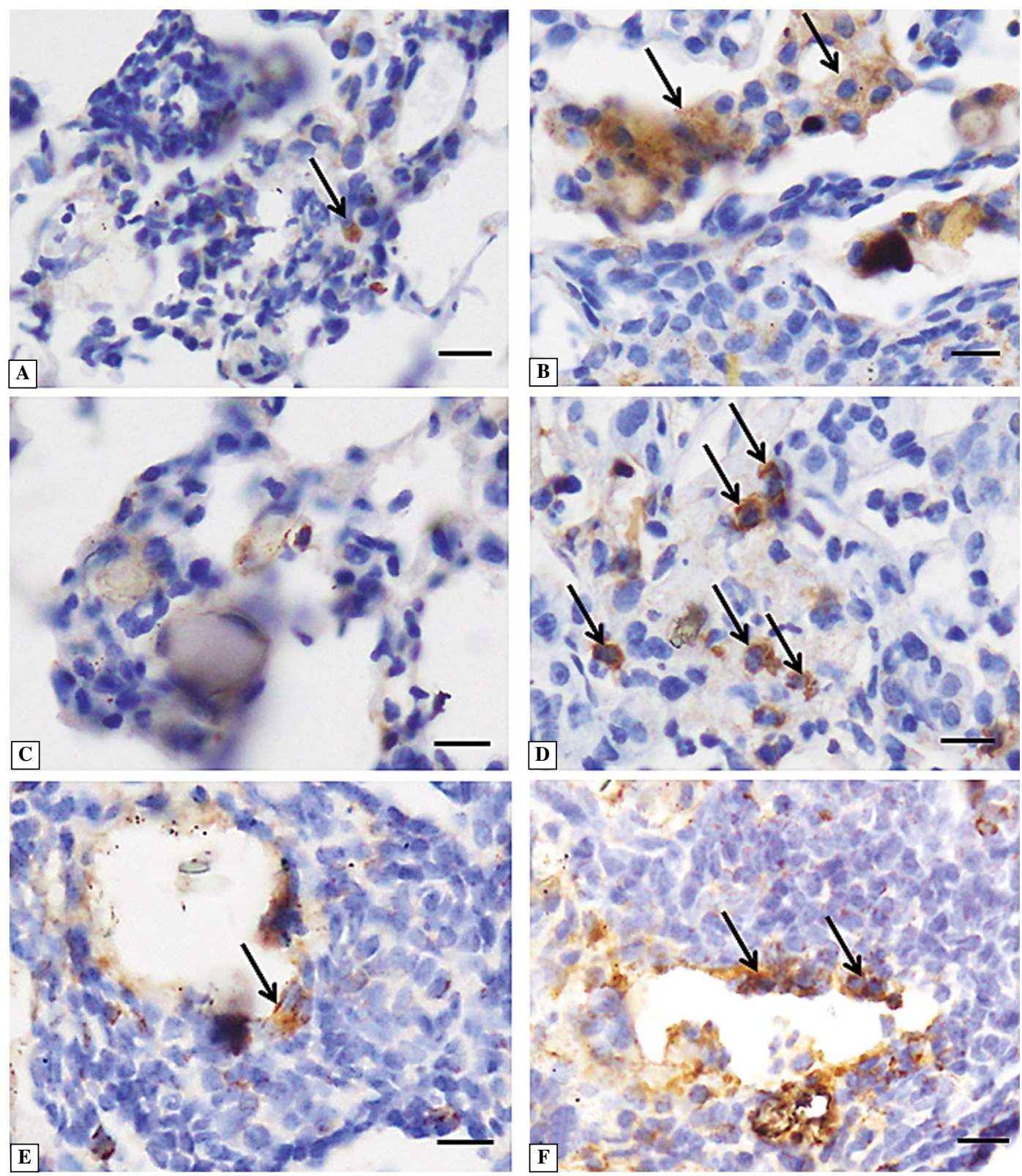

Figure 4. Inducible nitric oxide synthase (iNOS) immunoreactivity in lungs of mice treated with $3.0 \mathrm{mg}$ of Asian sand dust at 24 hours (A), 1 week (B), 1 month (C), 2 months (D), 3 months (E) and 4 months (F) after instillation. A, B, D. Macrophages (arrows) in the inflammatory lesions show positive immunolabelings for iNOS; C. Inflammatory lesions show negative immunolabelings for iNOS; E, F. Macrophages (arrows) in the granulomatous lesions show positive immunolabelings for iNOS. Bars $=20 \mu \mathrm{m}$

observed at 3 and 4 months. Multinucleated giant cells were also reported in the lung lesions at 2, 3, and 4 months following treatment. Small granuloma formation was observed in the lung lesions and scattered macrophages containing ASD particles were observed in the tracheobronchial lymph nodes at 4 months. These findings, including granuloma formation observed at low doses $(0.4 \mathrm{mg})$, were qualitatively similar to those reported in previous high dose $(3.0 \mathrm{mg})$ experiments [29].
In the aforementioned previous study [29], inflammatory responses to high doses of ASD were examined for up to 3 months after instillation; granulomatous lesions were observed at 2 and 3 months following treatment. In the present study, pathological examination during the longer period (4 months) was carried out in order to further elucidate the pathomorphogenesis of granulomatous lesions. The size of granulomatous lesions in mice treated with $3.0 \mathrm{mg}$ ASD gradually increased in the period from 
2 to 4 months after instillation. These lesions were composed of inflammatory cells such as macrophages and lymphocytes at 2 months, and inflammatory cells including macrophages and spindle-shaped cells at 4 months along with an increase in the interstitium. The interstitial substance was positive for collagen III by immunohistochemistry, suggesting that the fibrotic event is associated with the development and enlargement of granulomatous lesions after instillation of ASD particles.

Previous research [15] reported that the major mineralogical component of ASD is silica $\left(\mathrm{SiO}_{2}\right)$, which is derived mainly from feldspar and quartz (crystalline silica). Occupational exposure to crystalline silica leads to silicosis, which is characterized by a progressive granulomatous and fibrogenic response in the lung [21]. In experimental silicosis, the increase of collagen deposition in the lungs of rats over time has been reported [32]. Therefore, it is expected that the fibrotic response may progress and the size of granulomatous lesions become larger when observed at more advanced time points after instillation of a high dose of ASD.

The volume of the pulmonary extracellular matrix is, in part, regulated by matrix metalloproteinases (MMPs) and tissue inhibitor of metalloproteinases (TIMPs). MMPs play a central role in the regulation of multiple cellular functions such as cell proliferation, adhesion, migration, differentiation, angiogenesis, and apoptosis [33] and are capable of digesting extracellular matrix such as collagen and basement membrane components [34] and also acting as cell mediators. Because of its strong destructive ability, the activity of MMPs is strictly regulated by TIMPs [35]. TIMPs are also able to promote the proliferation of a variety of cells including fibroblasts [36]. Several pulmonary chronic diseases are proposed to result from the disturbance of the equilibrium between the synthesis and degradation of the pulmonary extracellular matrix; the activation of MMPs and TIMPs is involved in the process. Previous research has reported that the excessive or inappropriate expression of MMPs contributes to the pathogenesis of tissue destructive diseases such as pulmonary emphysema [37]. On the other hand, the development of pulmonary fibrosis is associated with an increase of TIMP-1 expression [38]. In addition, this increased expression of TIMP-1 appears to precede the increased accumulation of collagen [38]. The study reported here demonstrated the expression of MMP-9 in the acute inflammatory period and TIMP-1 in the chronic inflammatory period. Previously, the disruption of the basement membrane was observed in the lungs of mice treated with a high dose of ASD particles at 24 hours after instillation [28]. Expression of MMP-9 in the acute inflammatory lesions reported in this study may play a part in basement membrane disruption. Imbalance between MMP-9 and TIMP-1 was demonstrated in the lesions of acute pancreatitis [39]. As shown in experimental silicosis [40, 41], increased TIMP-1 expression, decreased MMP-9 expression and deposition of collagen in the lesions were also observed at the chronic period in this study. These findings suggest the possible association of the imbalance of expression between MMP and TIMP with the development of granulomatous lesions in the lungs of mice treated with ASD.

The role of cytokines and oxidative stress markers, IL-1 $\beta$ and inducible iNOS, respectively, has been reported in studies investigating the pathogenesis of pulmonary toxicity induced by crystalline silica $[42,43]$. Mice genetically deficient (knockout) in IL-1 $\beta$ or iNOS showed significantly reduced silicotic lesions [44]. The generation of IL- $1 \beta$ [43] and nitric oxide [44] was associated with the development of lung lesions including granuloma formation and fibrosis in experimental silicosis. In this study of ASD toxicity, IL- $1 \beta$ and iNOS expression were also demonstrated in both acute and chronic inflammatory lesions, suggesting that secondary released cytokines and oxidative stress generated in lesions may be involved in the development of the acute and chronic lung lesions induced by the intratracheally instilled ASD particles [45].

Silicosis is characterized in part by elevations in serum and bronchoalveolar lavage immunoglobulins in silicosis patients $[46,47]$ and experimentally exposed animals [20]. Another well-known health outcome associated with silica exposure is an increase in the incidence of autoimmune disorders [48, 49] including rheumatoid arthritis [50], scleroderma [51], systemic lupus erythematosus [52], and antineutrophilic cytoplasmic antibody-related nephritis [53]. Recent epidemiological studies on ASD have proposed that increased exposure to ASD particles is associated with the increased susceptibility to asthma, allergic rhinitis, contact dermatitis and conjunctivitis [1, 10, 54-57]. The previous study of ASD instillation in mice [28] demonstrated lymphocytic infiltration, which is characterized by a mixed population of many $\mathrm{T}$ lymphocytes and some B lymphocytes, at 2 months after instillation of ASD particles. In this current study, many plasma cells containing Russell bodies (called mott cells) and the accumulation of immunoglobulin G-positive cells were observed at the peribronchial lesions of 0.4 and $3.0 \mathrm{mg}$ treated mice at 4 months after instillation. In general, mott cells are regarded as plasma cells undergoing excessive synthesis of immunoglobulin and defective in secretion [31]. Mott 
cells are rare in normal tissue but frequently encountered in lymphoid tissues of murine and human autoimmune diseases [58] and in chronic inflammatory lesions with hyper-activation of the immune system by pathogens [59]. Thus, the presence of plasma cells containing Russell bodies observed in the ASD treated mice in this study suggests that the activation of antibody-mediated immunity occurred in addition to cell-mediated immunity, which could be in a state of hyper-immunization.

\section{Conclusions}

This study demonstrated that the low $(0.4 \mathrm{mg})$ and high $(3.0 \mathrm{mg})$ dose of mineralogical components of ASD particles, free from chemical and biological pollutants, induced granulomatous lesions in lung tissues at 2 months after intratracheal instillation. The dose $(0.4 \mathrm{mg})$ used in this study is similar to the volume of ASD particles that could have been inhaled on the seven consecutive days of the recorded highest concentration of suspended particulate matter (SPM, $0.898 \mathrm{mg} / \mathrm{m}^{3}$ ) in ASD season in Japan. In addition, the size of the granulomatous lesions induced by the intratracheal instillation of a high $(3.0 \mathrm{mg})$ dose of ASD gradually increased with collagen deposition over time. These findings suggest that ASD exposure has implications for public health. Since this study used the intratracheal instillation of ASD particles, with which is different from the atmospheric exposure of ASD in the natural environment, more experimental studies using the inhalation method with lower doses of ASD to mimic the natural low-level exposure occurring during the Kosa event season should be conducted in the future.

\section{Acknowledgements}

This work was supported in part by JSPS KAKENHI Grant Number 24580425, a Special Project (Assessment and Control of Dust Emission in Degraded Drylands of East Asia), MEXT, Japan for the research, authorship, and/or publication of this article, and by a research project grant awarded by the Azabu University.

\section{References}

1. Yang CY, Tsai SS, Chang CC, Ho SC. Effects of Asian dust storm events on daily admissions for asthma in Taipei, Taiwan. Inhal Toxicol. 2005;17:817-821. PMID: 16282159.

2. Bell ML, Levy JK, Lin Z. The effect of sandstorms and air pollution on cause-specific hospital admissions in Taipei, Taiwan. Occup Environ Med. 2008;65:104-111. doi: 10.1136/ oem.2006.031500.

3. Chan CC, Chuang KJ, Chen WJ, Chang WT, Lee CT, Peng CM. Increasing cardiopulmonary emergency visits by long-range transported Asian dust storms in Taiwan. Environ Res. 2008;106:393-400. PMID: 17959168.

4. Cheng, MF, Ho SC, Chiu HF, Wu TN, Chen PS, Yang CY. Consequences of exposure to Asian dust storm events on daily pneumonia hospital admissions in Taipei, Taiwan. J Toxicol Environ Health A. 2008;71:1295-1299. doi: 10.1080/15287390802114808.

5. Chiu HF, Tiao MM, Ho SC, Kuo HW, Wu TN, Yang CY. Effects of Asian dust storm events on hospital admissions for chronic obstructive pulmonary disease in Taipei, Taiwan. Inhal Toxicol. 2008;20:777-781. doi: 10.1080/08958370802005308.

6. Lai LW, Cheng WL. The impact of air quality on respiratory admissions during Asian dust storm periods. Int J Environ Health Res. 2008;18:429-450. doi: 10.1080/09603120802272227.

7. Kang JH, Liu TC, Keller J, Lin HC. Asian dust storm events are associated with an acute increase in stroke hospitalisation. JEpidemiol Community Health. 2013;67:125-131. doi: 10.1136/ jech-2011-200794.

8. Yang CY, Cheng MH, Chen CC. Effects of Asian dust storm events on hospital admissions for congestive heart failure in Taipei, Taiwan.J Toxicol Environ Health A. 2009;72:324-328. doi: 10.1080/15287390802529880.

9. Hwang SS, Cho SH, Kwon HJ. Effects of the severe Asian dust events on daily mortality during the spring of 2002, in Seoul, Korea. J Prev Med Public Health. 2005;38:197-202. PMID: 16315758.

10. Kwon H, Cho S, Chun Y, Lagarde F, Pershagen G. Effects of the Asian dust events on daily mortality in Seoul, Korea. Environ Res. 2002;90:1-5. PMID: 12359184.

11. Lee H, Kim H, Honda Y, Lim YH, Yi S. Effect of Asian dust storms on daily mortality in seven metropolitan cities of Korea. Atmos Environ. 2013;79:510-517. doi: 10.1016/j. atmosenv.2013.06.046.

12. Lee JT, Son JY, Cho YS. A comparison of mortality related to urban air particles between periods with Asian dust days and without Asian dust days in Seoul, Korea, 2000-2004. Environ Res. 2007;105:409-413. PMID: 17659273.

13. Chen YS, Sheen PC, Chen ER, Liu YK, Wu TN, Yang CY. Effects of Asian dust storm events on daily mortality in Taipei, Taiwan. Environ Res. 2004;95:151-155. PMID: 15147920.

14. Mori I, Nishikawa M, Tanimura T, Quan H. Change in size distribution and chemical composition of kosa (Asian dust) aerosol during long-range transport. Atmospheric Environment. 2003:37:4253-4263. doi: 10.1016/S1352-2310(03)00535-1.

15. Nishikawa M, Quan H, Morita M. Preparation and evaluation of certified reference materials for Asian mineral dust. Global Environ Res. 2000;1:103-113.

16. Calvert GM, Rice FL, Boiano JM, Sheehy JW, Sanderson WT. Occupational silica exposure and risk of various diseases: an analysis using death certificates from 27 states of the United States. Occup Environ Med. 2003;60:122-129. PMID: 12554840.

17. Kumagai N, Nishimura Y, Maeda M, Hayashi H, Otsuki T. Immunological effects of silica/asbestos. Nihon Eiseigaku Zasshi. 2010;65:493-499. PMID: 20885075.

18. Wu P, Miura $\mathrm{Y}$, Hyodoh $\mathrm{F}$ et al. Reduced function of CD4 $+25+$ regulatory $\mathrm{T}$ cell fraction in silicosis patients. Int J Immunopathol Pharmacol. 2006;19:357-368. PMID: 16831302.

19. Green FH, Vallyathan V, Hahn FF. Comparative pathology of environmental lung disease: an overview. Toxicol Pathol. 2007;35:136-147. PMID: 17325982.

20. Huang SH, Hubbs AF, Stanley CF et al. Immunoglobulin responses to experimental silicosis. Toxicol Sci. 2001;59:108-117. PMID: 11134550. 
21. Ishihara Y, Yasuhara T, Ishiyama S, Kawashima H, Miyasaka M, Miyazaki T. The role of leukocytes during acute phase inflammation in crystalline silica-induced lung injury. Exp Lung Res. 2001;27:589-603. PMID: 11597119.

22. Langley RJ, Kalra R, Mishra NC et al. A biphasic response to silica: I. Immunostimulation is restricted to the early stage of silicosis in lewis rats. Am J Respir Cell Mol Biol. 2004;30:823-829. PMID: 14742293.

23. Langley RJ, Mishra NC, Peña-Philippides JC, Hutt JA, Sopori ML. Granuloma formation induced by low-dose chronic silica inhalation is associated with an anti-apoptotic response in Lewis rats. J Toxicol Environ Health A. 2010;73:669-683. doi: 10.1080/15287390903578521.

24. Porter DW, Hubbs AF, Mercer R et al. Progression of lung inflammation and damage in rats after cessation of silica inhalation. Toxicol Sci. 2004;79:370-380. PMID: 15056817.

25. Friedetzky A, Garn H, Kirchner A, Gemsa D. Histopathological changes in enlarged thoracic lymph nodes during the development of silicosis in rats. Immunobiology. 1998;199:119-132. PMID: 9717672.

26. Porter DW, Millecchia L, Robinson VA et al. Enhanced nitric oxide and reactive oxygen species production and damage after inhalation of silica. Am J Physiol Lung Cell Mol Physiol. 2002;283:L485-L493. PMID: 12114212.

27. Ichinose T, Nishikawa M, Takano H et al. Pulmonary toxicity induced by intratracheal instillation of Asian yellow dust (Kosa) in mice. Environ Toxicol Pharmacol. 2005;20:48-56. doi: 10.1016/j.etap.2004.10.009.

28. Naota M, Mukaiyama T, Shimada A et al. Pathological study of acute pulmonary toxicity induced by intratracheally instilled Asian sand dust (kosa). Toxicol Pathol. 2010;38:1099-1110. doi: $10.1177 / 0192623310385143$.

29. Naota M, Shiotsu S, Shimada A et al. Pathological Study of Chronic Pulmonary Toxicity Induced by Intratracheally Instilled Asian Sand Dust (Kosa). Toxicol Pathol. 2013;41:48-62. doi: $10.1177 / 0192623312452490$.

30. Iwatsuki M, Kyotani T, Katsubar K. Fractional determination of elemental carbon and total soluble and insoluble organic compounds in airborne particulate matter by thermal analysis combined with extraction and heavy liquid separation. Bunseki Kagaku. 1998;43:879-884. doi: 10.2116/analsci.14.321.

31. Bavle RM. Bizzare plasma cell — mott cell.J Oral Maxillofac Pathol. 2013;17:2-3. doi: 10.4103/0973-029X.110682.

32. Reiser KM, Haschek WM, Hesterberg TW, Last JA. Experimental silicosis. II. Long-term effects of intratracheally instilled quartz on collagen metabolism and morphologic characteristics of rat lungs. Am J Pathol. 1983;110:30-40. PMID: 6295174.

33. Pardo A, Selman M. Matrix metalloproteases in aberrant fibrotic tissue remodeling. Proc Am Thorac Soc. 2006;3:383-388. PMID: 16738205.

34. Page-McCaw A, Ewald AJ, Werb Z. Matrix metalloproteinases and the regulation of tissue remodelling. Nat Rev Mol Cell Biol. 2007;8:221-233. PMID: 17318226.

35. Li C, Kuemmerle JF. Mechanisms that mediate the development of fibrosis in patients with Crohn's disease. Inflamm Bowel Dis. 2014;20:1250-1258. doi: 10.1097/ MIB.0000000000000043.

36. Nishimura K, Yamashita K, Kato Y et al. Inhibitory activity on matrix metalloproteinases and cell-proliferating activity of tissue inhibitor of metalloproteinases-1 (TIMP-1)-contrastive difference between human and bovine TIMP-1s on mouse cell proliferation. Growth Factors. 2005;23:135-142. PMID: 16019435.

37. Churg A, Zhou S, Wright JL. Series "matrix metalloproteinases in lung health and disease": Matrix metallopro- teinases in COPD. Eur Respir J. 2012;39:197-209. doi: 10.1183/09031936.00121611.

38. Ruiz V, Ordóñez RM, Berumen J et al. Unbalanced collagenases/TIMP-1 expression and epithelial apoptosis in experimental lung fibrosis. Am J Physiol Lung Cell Mol Physiol. 2003;285:L1026-L1036. PMID: 12882763.

39. Wereszczynska-Siemiatkowska U, Siemiatkowski A, Swidnicka-Siergiejko A, Mroczko B, Dabrowski A. The imbalance between matrix metalloproteinase 9 and tissue inhibitor of metalloproteinase 1 in acute pancreatitis. $Z$ Gastroenterol. 2015;53:199-204. doi: 10.1055/s-0034-1385705.

40. Pardo A, Pérez-Ramos J, Segura-Valdez L, Ramírez R, Selman M. Expression and localization of TIMP-1, TIMP-2, MMP-13, MMP-2, and MMP-9 in early and advanced experimental lung silicosis. Ann NY Acad Sci. 1999;878:587-589. PMID: 10415781.

41. Pérez-Ramos J, Segura-Valdez ML, Vanda B, Selman M, Pardo A. Matrix metalloproteinases 2, 9, and 13, and tissue inhibitors of metalloproteinases 1 and 2 in experimental lung silicosis. Am J Respir Crit Care Med. 1999;160:1274-1282. PMID: 10508819.

42. Castranova V, Porter D, Millecchia L, Ma J, Hubbs A, Teass A. Effect of inhaled crystalline silica in a rat model: time course of pulmonary reactions. Mol Cell Biochem. 2002; 234/235:177-184. PMID: 12162431.

43. Guo J, Gu N, Chen J et al. Neutralization of interleukin-1 beta attenuates silica-induced lung inflammation and fibrosis in C57BL/6 mice. Arch Toxicol. 2013;87:1963-1973. doi: 10.1007/s00204-013-1063-Z.

44. Srivastava KD, Rom WN, Jagirdar J, Yie TA, Gordon T, Tchou-Wong KM. Crucial role of interleukin-1beta and nitric oxide synthase in silica-induced inflammation and apoptosis in mice. Am J Respir Crit Care Med. 2002;165:527-533. PMID: 11850347.

45. Yeo NK, Hwang YJ, Kim ST, Kwon HJ, Jang YJ. Asian sand dust enhances rhinovirus-induced cytokine secretion and viral replication in human nasal epithelial cells. Inhal Toxicol. 2010;22:1038-1045. doi: 10.3109/08958378.2010.516282.

46. Beshir S, Shaheen WA, Elserougy S, Aziz HM. Serum autoantibodies in silicosis and non-silicosis cement workers. $\mathrm{Am}$ J Ind Med. 2015;58:238-244. doi: 10.1002/ajim.22413.

47. Yao SQ, He QC, Yuan JX et al. Role of Fas/FasL pathway-mediated alveolar macrophages releasing inflammatory cytokines in human silicosis. Biomed Environ Sci. 2013;26:930-933. doi: 10.3967/bes2013.024.

48. Maeda M, Nishimura $\mathrm{Y}$, Kumagai $\mathrm{N}$ et al. Dysregulation of the immune system caused by silica and asbestos. J Immunotoxicol. 2010;7:268-278. doi: 10.3109/1547691X.2010.512579.

49. Parks CG, Conrad K, Cooper GS. Occupational exposure to crystalline silica and autoimmune disease. Environ Health Perspect. 1999;107(Suppl. 5):793-802. PMID: 10970168.

50. Cooper GS. Occupational exposures and risk of rheumatoid arthritis: continued advances and opportunities for research. J Rheumatol. 2008;35:950-952. PMID: 18528947.

51. Martin JR, Griffin M, Moore E et al. Systemic sclerosis (scleroderma) in two iron ore mines. Occup Med (Lond). 1999;49:161-169. PMID: 10451597.

52. Parks CG, Cooper GS. Occupational exposures and risk of systemic lupus erythematosus: a review of the evidence and exposure assessment methods in population- and clinic-based studies. Lupus. 2006;15:728-736. PMID: 17153843.

53. Tervaert JW, Stegeman CA, Kallenberg CG. Silicon exposure and vasculitis. Curr Opin Rheumatol. 1998;10:12-17. PMID: 9448985. 
54. Chen YS, Yang CY. Effects of Asian dust storm events on daily hospital admissions for cardiovascular disease in Taipei, Taiwan. J Toxicol Environ Health A. 2005;68:1457-1464. PMID: 16076758.

55. Im HJ, Kwon HJ, Ha M et al. Public perceptions of the risk of Asian dust storms in Seoul and its metropolitan area. JPrev Med Public Health. 2006;39:205-212. PMID: 16764494.

56. Kanatani KT, Ito I, Al-Delaimy WK et al. Desert dust exposure is associated with increased risk of asthma hospitalization in children. Am J Respir Crit Care Med. 2010;182:1475-1481. doi: 10.1164/rccm.201002-0296OC.
57. Yang CY. Effects of Asian dust storm events on daily clinical visits for conjunctivitis in Taipei, Taiwan. $J$ Toxicol Environ Health A. 2006;69:1673-1680. PMID: 16864418.

58. Honjo K, Kubagawa Y, Suzuki Y et al. Enhanced auto-antibody production and Mott cell formation in $\mathrm{F} c \mu \mathrm{R}$-deficient autoimmune mice. Int Immunol. 2014;26:659-672. doi: 10.1093/intimm/dxu070.

59. Ensari A, Savas B, Okcu Heper A, Kuzu I, Idilman R. An unusual presentation of Helicobacter pylori infection: so-called "Russell body gastritis". Virchows Arch. 2005;446:463-466. PMID: 15744498. 